\title{
Effect of Isosporiasis Prevention with Toltrazuril on Long-Term Pig Performance
}

\author{
K. Rypula, ${ }^{1}$ M. Porowski, ${ }^{1}$ J. Kaba, ${ }^{2}$ M. Gorczykowski, ${ }^{3}$ and A. Deniz ${ }^{4}$ \\ ${ }^{1}$ Division of Infectious Diseases and Veterinary Administration, Department of Epizootiology with Clinic of Birds and Exotic Animals, \\ Faculty of Veterinary Medicine, Wrocław University of Environmental and Life Sciences, Grunwaldzki Square 45, \\ 50-366 Wrockaw, Poland \\ ${ }^{2}$ Division of Infectious Diseases and Epidemiology, Department of Large Animal Diseases, Faculty of Veterinary Medicine, \\ Warsaw University of Life Sciences-SGGW, Nowoursynowska 159c, 02-776 Warsaw, Poland \\ ${ }^{3}$ Divison of Parasitology, Department of Internal Diseases with Clinic of Horses, Dogs and Cats, Faculty of Veterinary Medicine, \\ Agricultural University of Wrocław, Poland \\ ${ }^{4}$ Bayer HealthCare Animal Health, Leverkusen, Germany
}

Correspondence should be addressed to K. Rypula, krzysztof.rypula@up.wroc.pl

Received 10 October 2011; Accepted 16 November 2011

Academic Editor: Kunio Ohmiya

Copyright ( $) 2012 \mathrm{~K}$. Rypula et al. This is an open access article distributed under the Creative Commons Attribution License, which permits unrestricted use, distribution, and reproduction in any medium, provided the original work is properly cited.

The efficacy of toltrazuril treatment was assessed in two experiments in Polish swine herds. Experiment 1 included a toltrazuril treatment group, Group A $(n=410)$, and untreated control, Group B $(n=386)$. Time to sale in Group A was 108 days versus 120 days for Group B, with average body weights at sale of $114.2 \mathrm{~kg}$ and $108.8 \mathrm{~kg}$, respectively $(P<0.05)$. In experiment 2 , the health status and body weight gain of 238 piglets treated with toltrazuril (Group D) were compared to 235 untreated piglets (Group K). A similar difference was observed in average body weights of slaughtered animals, being on average $104 \mathrm{~kg}$ in Group D and $101 \mathrm{~kg}$ in Group K $(P<0.01)$. Animals from Group D were slaughtered 5 days earlier than animals from Group K (day 166 versus day 171). Data from clinical trials suggest treatment of coccidiosis with toltrazuril offering potential for improved animal welfare and yields, however this has remained unproven in field conditions in large swine production facilities. The present study confirms the efficacy of toltrazuril treatment when used in the field and the subsequent positive impact on time to weaning, time to market, and on weight gain at all time points.

\section{Introduction}

Diarrhoea remains a significant, though often underappreciated, issue in both economic and welfare terms on many swine farms worldwide. The most common cause of severe diarrhoea in pigs aged 5-20 days is coccidiosis, caused by infection by the near ubiquitous Eimeriidae coccidium Isospora suis [1-3], which has been found in over $75 \%$ of farms examined in Ireland, Germany, the Netherlands, Greece, Austria, and Switzerland $[4,5]$. A recent study into I. suis prevalence in Poland found that $90 \%$ of farms tested positive [4].

The I. suis parasite lifecycle has prepatent and patent phases; the prepatent usually lasts 5-7 days, and the patent lasts 5-16 days. Along with the characteristic 5-8 days of creamy yellow diarrhoea, serious damage to the mucosal crypts and villi of suckling piglets due to I. suis has previously been reported $[1,3]$. The rupture of cells of the villi of gut mucosa during infection causes fibrinous enteritis and longterm damage to the gut, leaving piglets more susceptible to other infections, such as E. coli and Clostridium perfringens $[7,8]$. Maturity of mucosa villous at weaning is of special importance in terms of postweaning feeding performance $[9,10]$. Damage to the gut can also have a significant impact on the long-term growth and wellbeing of the piglet, causing decreases in weight at weaning of as much as $1 \mathrm{~kg}$ [6], even in asymptomatic pigs [11].

As I. suis infection is spread through faecal matter, hygiene is a key component of coccidiosis prevention. In theory, clearing farrowing pens and a programme of thorough, 
ongoing cleansing with an effective oocysticide may to some extent control the reappearance of coccidiosis, but not totally [12]. However, as I. suis infection is so prevalent, this is, in practice, not effective strategy.

Treatment with sulphonamides and diclazuril in experimental studies has not proven effective in managing coccidiosis, but treatment simplicity and efficacy were recently significantly improved by the approval of toltrazuril (Baycox $5 \%$, Bayer Animal Health) for the treatment of coccidiosis in swine. Individual treatment of piglets around day 4 of life with $0.4 \mathrm{~mL} / \mathrm{kg}$ toltrazuril has proven to be the most effective treatment option available $[5,6]$.

A number of studies have reported that treatment with toltrazuril can improve the health of the gut and increased weight gain $[6,8,11]$, reduce use of antibiotics [13] and rate of diarrhoea in early life [8], and improve postweaning feed conversion ratios $[9,10]$.

The present study sets out to investigate the efficacy of toltrazuril treatment in swine herds in field conditions in Poland to ascertain whether the efficacy reported in clinical studies can be replicated in the field, particularly in relation to increased weight gain, reduced need for veterinary intervention and faster time to market.

\section{Materials and Methods}

2.1. Experiment 1. The therapeutic efficacy of a single oral treatment with toltrazuril (Baycox 5\%, Bayer Animal Health) $(0.4 \mathrm{~mL} / \mathrm{kg} \mathrm{BW}$, equivalent to $20 \mathrm{mg}$ toltrazuril $/ \mathrm{kg} \mathrm{BW})$ was examined on two pig farms in Lower Silesia and Mazowia voividships, Poland.

Farm 1 operated a closed, continuous flow with all-inall-out (AIAO) system of production cycle with a basic herd of 130 hybrid Polish Landrace x Polish Large White sows. Study groups comprising 10 sows were created twice a week during the study period. All welfare conditions in the labour sections as well as in the breeding and fattening sections were satisfactory. A history of I. suis infection was confirmed on Farm 1.

Farm 2 also operated a closed, continuous flow with AIAO system of production cycle, with a basic herd of 450 hybrid PIC sows. Study groups of 20 sows were created once a week during the study period. All welfare conditions in the labour sections as well as in the breeding and fattening sections were satisfactory. All weaning piglets were sold on. A history of I. Suis infection was confirmed on Farm 2.

The study was conducted on 383 pigs from Farm 1 and on 413 pigs from Farm 2 based on simple randomisation. On both farms, the group treated with toltrazuril was labelled Group A (Farm 1, $n=205$; Farm 2, $n=205$ ) and the nontreated control group as Group B (Farm 1, $n=178$; Farm $2, n=208$ ) (Figure 1). Selection criteria were based on the age of piglets and number of piglets in the litter.

Treatment efficacy assessment was based on weight gain from day 4 (first day of toltrazuril administration) through to day 14-defined as the first stage preweaning periodand from day 14 to the day of weaning - the second stage preweaning period. Piglets were weaned when 28 and 25 days

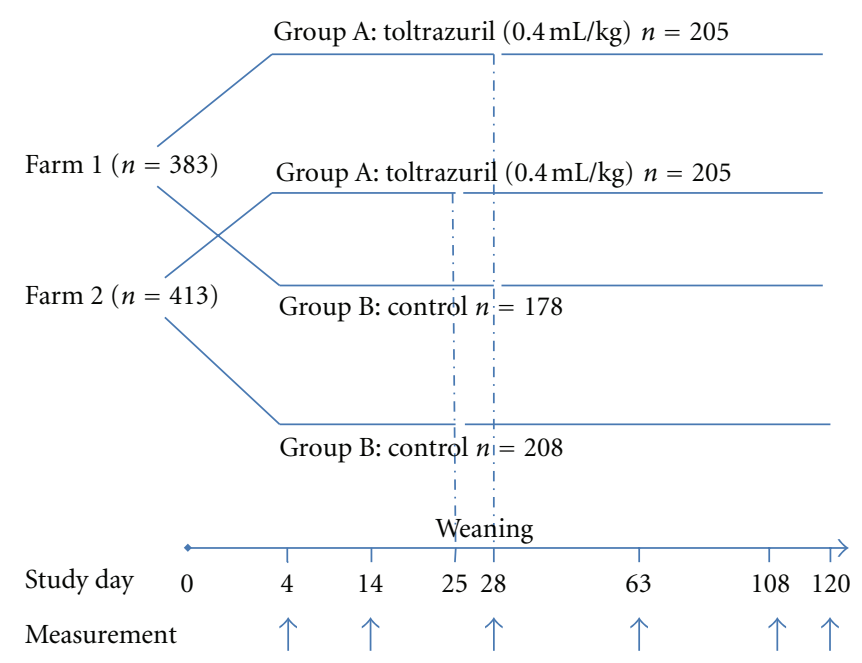

Figure 1: Experiment 1: Study design.

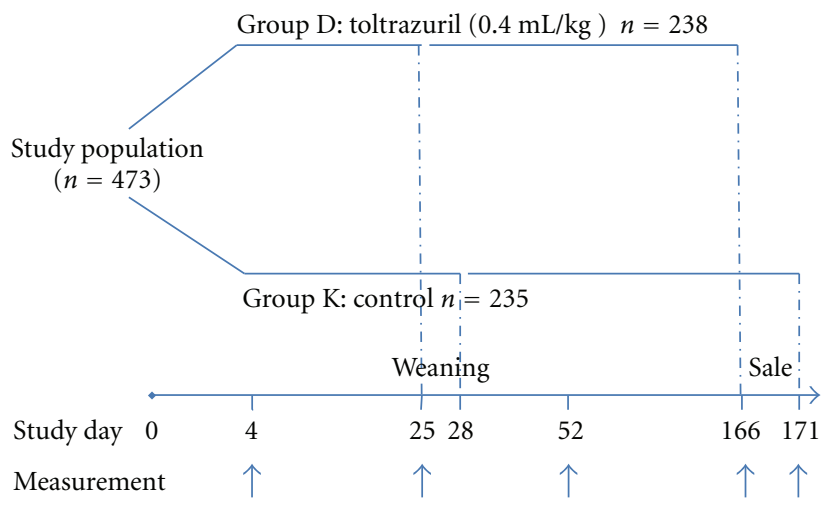

FIgURE 2: Experiment 2: Study design.

old on farm 1 and 2, respectively. In addition, the frequency of medical interventions (mainly antibiotic injections) required for diarrhoea control was measured. Prior to treatment with toltrazuril, the presence of $I$. suis infection was confirmed by parasitological examination of $10 \%$ of piglet faeces in all experimental groups. Oocysts were confirmed in all collected samples.

2.2. Experiment 2. The second experiment was carried out on a production facility in Mazovia viovodship, Poland with a closed, AIAO production cycle and a basic herd of 1,700 hybrid PIC sows and 10 hybrid Polish Landrace x Polish Large White boars. Study groups comprising 90 sows were created once a week during the production cycle. All welfare conditions in the labour sections as well as in the breeding and fattening sections were satisfactory.

The study evaluated the health status and body weight gain of 238 piglets treated with a single dose of toltrazuril $(0.4 \mathrm{~mL} / \mathrm{kg} \mathrm{BW}$, equivalent to $20 \mathrm{mg}$ toltrazuril $/ \mathrm{kg} \mathrm{BW})$ (Group D) at day 4 of life compared to 235 untreated piglets in the control group (Group K) (Figure 2). The choice of the piglets was conducted as in experiment 1. 
TABLe 1: Experiment 1: Mean piglet body weight.

\begin{tabular}{|c|c|c|c|c|c|c|c|}
\hline & & \multicolumn{6}{|c|}{ Piglet body weight } \\
\hline & & Day 4 & Day 14 & Day 28 & Day 63 & Day 108 & Day 120 \\
\hline \multirow{2}{*}{ Farm 1} & Group A & $2093 \mathrm{~g} \pm 390$ & $4163 \mathrm{~g}^{*} \pm 854$ & $7745 \mathrm{~g} \pm 1843$ & $21300 g^{*} \pm 1351$ & $114200 \mathrm{~g}^{*} \pm 3856$ & - \\
\hline & Group B & $2125 \mathrm{~g} \pm 420$ & $3602 g \pm 571$ & $6333 g \pm 933$ & $20500 \mathrm{~g} \pm 1381$ & - & $108800 \mathrm{~g} \pm 3036$ \\
\hline \multirow{2}{*}{ Farm 2} & Group A & $2065 g \pm 413$ & $3910 \mathrm{~g}^{*} \pm 879$ & $6490 g^{*} \pm 1337$ & - & - & - \\
\hline & Group B & $2062 \mathrm{~g} \pm 374$ & $3040 \mathrm{~g} \pm 440$ & $5385 \mathrm{~g} \pm 1118$ & - & - & - \\
\hline
\end{tabular}

$* P<0.05$.

TABLe 2: Experiment 2: Mean piglet body weight.

\begin{tabular}{lccccc}
\hline & & \multicolumn{4}{c}{ Piglet body weight } \\
& Day 4 & Day $25^{\mathrm{a}} / 28^{\mathrm{b}}$ & Day 52 & Day 166 & Day 171 \\
\hline Group D & $1530 \mathrm{~g} \pm 103$ & $6180 \mathrm{~g}^{*} \pm 271$ & $31000 \mathrm{~g}^{*} \pm 1068$ & $104000 \mathrm{~g}^{*} \pm 7026$ \\
Group K & $1540 \mathrm{~g} \pm 97$ & $5830 \mathrm{~g} \pm 245$ & $27900 \mathrm{~g} \pm 1407$ & - & $101000 \mathrm{~g} \pm 7251$ \\
\hline
\end{tabular}

$* P<0.01$.

${ }^{\mathrm{a}}$ Day of weaned piglets in group D.

${ }^{b}$ Day of weaned piglets in group $\mathrm{K}$.

Assessments of health status and body weight gain were made on the 4th day of life (start of treatment), on the day of weaning, when moving from the breeding sector to the fattening sector, and finally on the day of sale.

Statistical calculations in both experiments were carried out with Mann-Whitney $U$ test and $\chi^{2}$ (chi-squared) test with the use of Statistica v. 6.1 software.

\section{Results}

3.1. Experiment 1. Body weight gain of the piglets in Group A (treatment group), between day 4 and day 14, was $2070 \mathrm{~g}$ and $1845 \mathrm{~g}$ in Farms 1 and 2, respectively. Additional body weight gain in Farms 1 and 2 in the second phase of weaning (day 14 to weaning) was $3582 \mathrm{~g}$ and $2580 \mathrm{~g}$, respectively.

Piglets in Group B (control group) gained $1477 \mathrm{~g}$ on Farm 1 and $978 \mathrm{~g}$ on Farm 2 between day 4 and 14, and additional $2737 \mathrm{~g}$ and $2345 \mathrm{~g}$, respectively, between day 14 and weaning.

In the time to weaning, piglets in Group A required 6 medical interventions in both Farms 1 and 2, compared to 13 and 18 in Farms 1 and 2, respectively, for those in Group B.

Piglets on Farm 1 were also followed through to sale to ascertain the impact of treatment on long-term growth. At transfer from weaning to a feeding group at day 63, average body weight was $21300 \mathrm{~g}$ for Group A versus $20500 \mathrm{~g}$ in Group B. Time to sale in Group A was 108 days for Group A versus 120 days for Group B, with average body weights at sale of $114200 \mathrm{~g}$ and $108800 \mathrm{~g}(P<0.05)$, respectively (Table 1).

3.2. Experiment 2. Piglets in experiment 2 of the study were assessed at days $4,25,52,166$, and 171 . Those piglets in treatment group $\mathrm{D}$ ( $n=238$ at birth, $n=210$ at weaning) weaned on average at 25.6 days, while those in the control group K ( $n=235$ at birth, $n=194$ at weaning) weaned on average at 28 days.
There was a statistically significant difference $(P=0.03)$ in relation to average daily weight gain between Group D (221 g) and Group K (204 g) at day 25, and a statistically significant difference was also observed between Groups D and $\mathrm{K}$ in relation to reports of diarrhoea prior to weaning4 versus 22 cases, respectively $(P<0.01)$. Body weight at weaning and cases of digestive disorders or death showed no statistical difference between groups.

After moving animals to the breeding sector on day 25, average body weight of the animals in the group receiving the toltrazuril was $6180 \mathrm{~g}$ and was greater than the body weight of the piglets in Group K $(P<0.01)$. After weaning, animals were kept in their groups for fattening until day 52. Average body weight of animals transferred to the fattening sector was $31000 \mathrm{~g}$ and $27900 \mathrm{~g}$, respectively, for Groups D and K. A similar difference was observed in average body weights of slaughtered animals, being on average $104000 \mathrm{~g}$ in Group D and $101000 \mathrm{~g}$ in Group K (Table 2). Animals from Group D were slaughtered 5 days earlier than animals from Group $\mathrm{K}$ (day 166 versus day 171).

\section{Discussion}

Alongside the obvious short-term impact of diarrhoeal disease, coccidiosis infection is responsible for significant damage to the gut of piglets, regardless of whether or not they are symptomatic. This damage can have serious longterm effects on their health and growth, leading to significant losses for the pig producer.

A number of experimental trials have demonstrated the impact of toltrazuril on key production criteria including daily weight gain, where treatment-related increases in weight gain have been recorded at $37 \mathrm{~g} /$ day to day 28 [6], $25 \mathrm{~g} /$ day to weaning [11], and $14 \mathrm{~g} /$ day between days 21 and 105 [9], and toltrazuril treatment-related feed conversion rates in weaner-finisher herds of 2.41 versus 2.63 [10] and 1.6 versus 1.77 [9]. Treatment with toltrazuril has also been 
shown to increase body weight at weaning by $670 \mathrm{~g}(P<$ $0.05)[6]$ and $326.6 \mathrm{~g}(P=0.044)$ [8] compared to placebo.

While not directly investigating daily weight gains or feed conversion rates, the present study has confirmed the significant improvements in yield suggested by trial results are indeed replicable in the "real world", with treatmentrelated weight gain of $1412 \mathrm{~g}$ and $350 \mathrm{~g}$ at weaning and $5400 \mathrm{~g}$ and $3000 \mathrm{~g}$, respectively, for experiments 1 and 2 at time to market. It was also notable that all treatment groups reached weaning ( 3 days) and market weight (between 5 and 12 days) substantially earlier than the untreated controls.

Cases of diarrhoea were also significantly reduced in treated groups, reflecting the previously reported findings of McOrist and others [9] and Westphal and others [8]. The absence of significant reductions in cases of digestive disorders and death among groups in this study is likely to reflect the already low mortality associated with coccidiosis infection along with the multiplicity of infections (Porcine Respiratory Disease Complex) affecting piglets during the weaning phase in a commercial swine production facility.

The results of this study, performed in field conditions, suggest that the use of a single application of toltrazuril is likely to produce results similar to those noted in experimental trials. These results support the view that, in real-world conditions, metaphylaxis with toltrazuril is extremely effective at managing the impact of $I$. suis infection on the health and growth of piglets, leading to substantial improvements in weight gain that continue over the lifetime of the pig, bringing pigs to market weight substantially faster and at a greater weight.

\section{Acknowledgment}

The authors thank gratefully Bayer and Ketchum Pleon Limited.

\section{References}

[1] B. P. Stuart, D. S. Lindsay, J. V. Ernst, and H. S. Gosser, "Isospora suis enteritis in piglets," Veterinary Pathology, vol. 17, no. 1, pp. 84-93, 1980.

[2] Y. Robinson, M. Morin, C. Girard, and R. Higgins, "Experimental transmission of intestinal coccidiosis to piglets: clinical, parasitological and pathological findings," Canadian Journal of Comparative Medicine, vol. 47, no. 4, pp. 401-407, 1983.

[3] H. C. Mundt, A. Joachim, M. Becka, and A. Daugschies, "Isospora suis: an experimental model for mammalian intestinal coccidiosis," Parasitology Research, vol. 98, no. 2, pp. 167-175, 2006.

[4] A. Torres, "Prevalence study of Isospora suis in Europe," in Proceedings of the 18th IPVS Congress, Hamburg, Germany, 2004.

[5] H. C. Mundt, A. Cohnen, A. Daugschies et al., "Occurrence of Isospora suis in Germany, Switzerland and Austria," Journal of Veterinary Medicine Series B, vol. 52, no. 2, pp. 93-97, 2005.

[6] A. Scala, F. Demontis, A. Varcasia et al., "Toltrazuril and sulphonamide treatment against naturally Isospora suis infected suckling piglets: is there an actual profit?" Veterinary Parasitology, vol. 163, no. 4, pp. 362-365, 2009.
[7] C. Chae, D. Kwon, O. Kim et al., "Diarrhoea in nursing piglets associated with coccidiosis: prevalence, microscopic lesions and coexisting microorganisms," Veterinary Record, vol. 143, no. 15 , pp. 417-420, 1998.

[8] B. Westphal, U. Bernemann, and L. Kathmann, "Mixed Isospora suis and Clostridium perfringens infections in suckling pigs immediately post partum?" Tierarztliche Umschau, vol. 62, no. 12, pp. 682-689, 2007.

[9] S. McOrist, A. Blunt, H. El-Sheikha, A. Morillo-Alujas, M. Ocak, and A. Deniz, "Evaluation of efficacy of oral toltrazuril (Baycox 5\%) for the improvement of post-weaning gut health in pigs," The Pig Journal, vol. 63, pp. 73-79, 2010.

[10] S. McOrist, D. Spiru, M. Ocak, and A. Deniz, "Evaluation of efficacy of oral toltrazueril (Baycox 5\%) for the improvement of post-weaning gut health in pigs in Romania," in Proceedings of the 21st IPVS Congress, Vancouver, Canada, July 2010.

[11] D. Maes, P. Vyt, P. Rabaeys, and D. Gevaert, "Effects of toltrazuril on the growth of piglets in herds without clinical isosporosis," Veterinary Journal, vol. 173, no. 1, pp. 197-199, 2007.

[12] E. Straberg and A. Daugschies, "Control of piglet coccidiosis by chemical disinfection with a cresol-based product (Neopredisan 135-1)," Parasitology Research, vol. 101, no. 3, pp. 599604, 2007.

[13] S. J. Driesen, V. A. Fahy, and P. G. Carland, "The use of toltrazuril for the prevention of coccidiosis in piglets before weaning," Australian Veterinary Journal, vol. 72, no. 4, pp. 139141, 1995. 

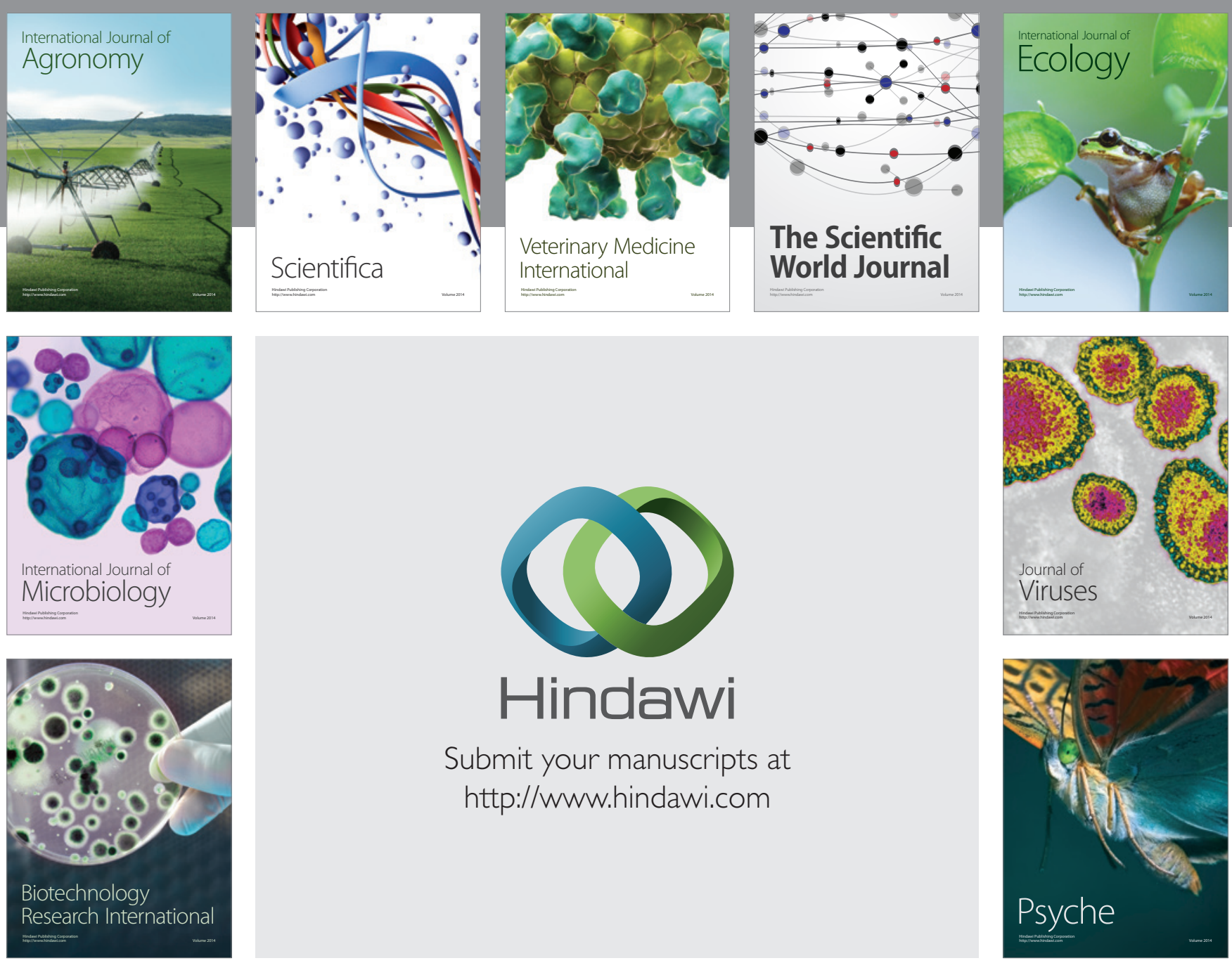

Submit your manuscripts at

http://www.hindawi.com
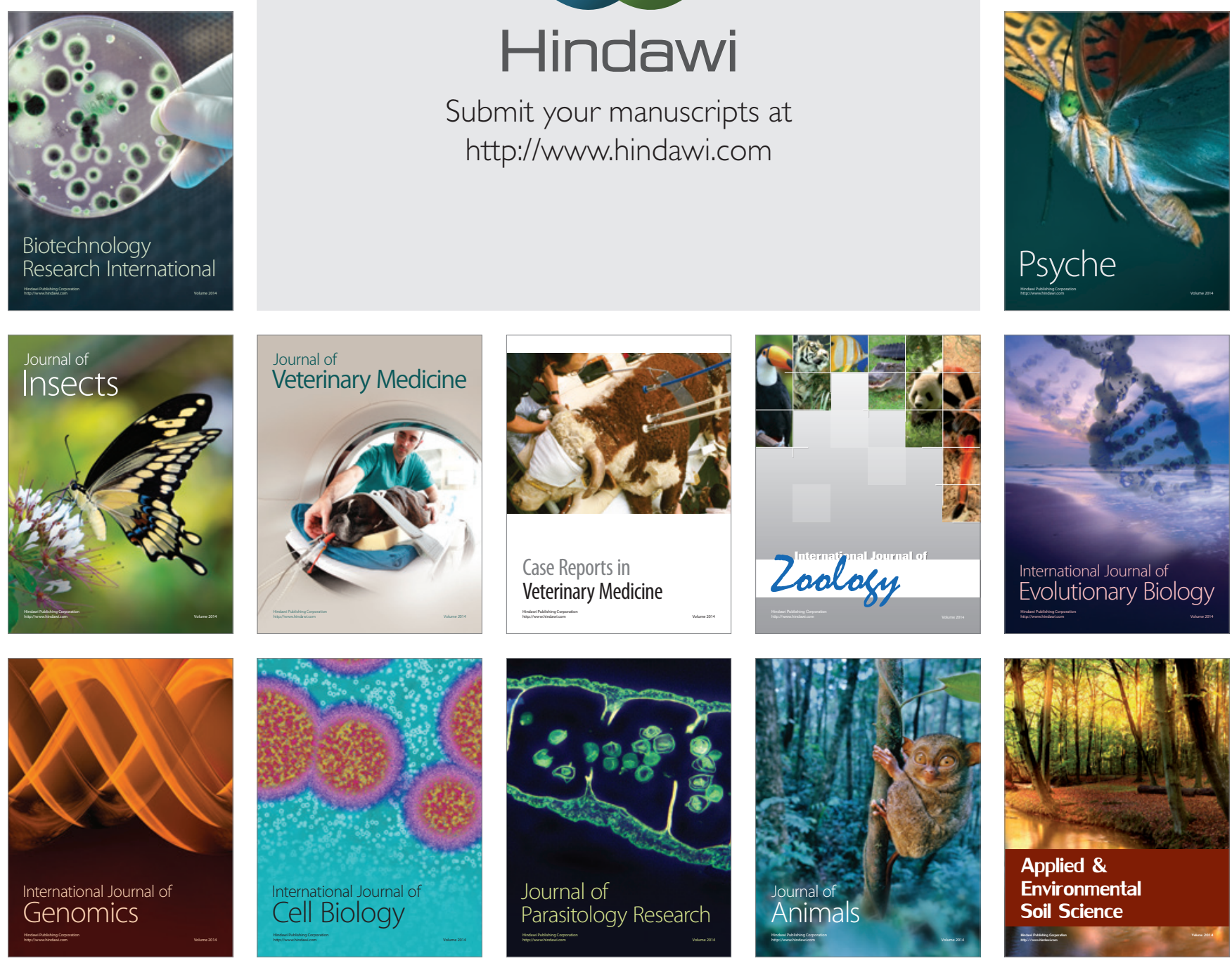